Quest Journals

Journal of Research in Humanities and Social Science

Volume 2 Issue 11 (2014) pp: 60-69

ISSN(Online) : 2321-9467

www.questjournals.org

Research Paper

\title{
Why do community-based athletes choose to participate in a modified, low-risk form of boxing? An interpretative phenomenological analysis
}

\author{
Paul Perkins, ${ }^{1}{ }^{2}$ Allan Hahn, ${ }^{1,}, 5 \& 6$ Richard Keegan, ${ }^{1 \&} 3$ Irmani Collis ${ }^{2}$ \\ ${ }^{1}$ University of Canberra Research Institute for Sport and Exercise, Canberra, Australia \\ ${ }^{2}$ Canberra Police Community Youth Club, Canberra, Australia \\ ${ }^{3}$ Sport and Exercise Discipline, Faculty of Health, University of Canberra, Australia \\ ${ }^{4}$ Queensland Academy of Sport Centre of Excellence for Applied Sport Science Research, Brisbane, Australia \\ ${ }^{5}$ Griffith University School of Engineering, Brisbane, Australia \\ ${ }^{6}$ Victoria University School of Engineering and Science, Melbourne, Australia
}

Received 17 November, 2014; Accepted 29 November, 2014 (C) The author(s) 2014. Published with open access at www.questjournals.org

\begin{abstract}
Over the past eight years a modified, low-risk form of boxing known as Box'Tag has emerged in Australia. It has been designed to emphasise high levels of fitness, skill and personal enjoyment, while excluding those aspects of traditional boxing that have raised medical, ethical and legal concerns. Strikes to the head are prohibited, as are any impacts above a moderate level of force. Although uptake to date has been encouraging, a question remains as to whether Box'Tag can be developed in a way that will lead to sustainable large-scale community participation.

Presently, there are only a few exemplar clubs where Box'Tag programs are being conducted. The purpose of the current study was to investigate, analyze and interpret one of these programs to discover the factors that have influenced a number of community-based athletes to have a two-year involvement with a modified, lowrisk form of boxing. This was accomplished by allowing the participants to recall their experiences free of any judgment and by making sense of their perceptions through an interpretative phenomenological analysis. Sustained participation in Box'Tag appears to have resulted from a sense of belonging to a special community, strong coach-athlete relationships, perception that the training is purposeful and a focus on safety.
\end{abstract}

Keywords:- Box'Tag, Interpretative phenomenological analysis, Modified boxing, Qualitative inquiry, Sport for development

\section{INTRODUCTION}

Boxing is a subject that has long been debated [1]. Since the 1860s the sport has diverged into two clearly differentiated forms - professional and amateur [2]. The evolution of professional boxing has been driven largely by profit motives whereas amateur boxing has placed greater emphasis on the welfare and safety of participants. At present, though, amateur boxing is changing and starting to resemble its professional counterpart $[3]$ and this is perhaps creating a need for a new version of the sport.

Common objections to boxing are that it exposes participants to risk of serious brain injury and even death [4], involves deliberate intent to harm the opponent [5] and consists of activities that under other circumstances could result in the perpetrators being convicted of criminal assault [6].

Concerns also have been raised that boxing might have negative social effects by glamorizing and modeling physical violence and that it entails exploitation of vulnerable young people [7]. Based on the objections, there have been calls for boxing to be outlawed [8] and in some countries a ban on professional boxing has been implemented, though in most cases it has subsequently been rescinded.

Supporters of boxing dispute many of the objections and contend that the sport has numerous positive features. For example, they point out that boxing is an excellent vehicle for development of physical fitness and that boxing-related activities are being widely used in attempts to address the global problem of increasing incidence of diseases caused by sedentary lifestyles [9].In addition, it is claimed that boxing can build desirable personality traits [10] and can yield considerable social benefits in disadvantaged communities where few sporting opportunities exist [11].

\footnotetext{
*Corresponding Author: Paul Perkins

${ }^{1}$ University of Canberra Research Institute for Sport and Exercise, Canberra, Australia
} 
Several experts have noted that the sport has important aesthetic and symbolic qualities that have allowed it to act as a medium for transmission of artistic and cultural values and an agent of social change [12,13]. Given that some of the arguments both for and against boxing can be seen as having merit, a question arises as to whether it might be possible to develop a new form of the sport that overcomes the objections while retaining the beneficial elements. A leading medical authority has suggested specific modifications, including exclusion of the head and neck as targets and the introduction of special gloves with greatly increased capacity for impact absorption [14].

A modified form of boxing called Box'Tag incorporating these recommendations and other safety measures has recently emerged in Australia. It has gained a foothold in a few exemplar clubs but its potential for widespread uptake remains uncertain.

\section{OVERVIEW OF RESEARCH STRATEGY}

An interpretative phenomenological analysis (IPA) was used in the present study to discover the significant factors that have influenced community-based athletes to have a two-year involvement with a Box'Tag program operating at Erindale in southern Canberra, Australia, where a Box'Tag Field Research Centre has been established through a partnership between the Canberra Police Community Youth Club (Canberra PCYC) and the University of Canberra Research Institute for Sport \& Exercise.

The study was framed by a constructivist ontological understanding that the individuals could construct different versions of the reality and guided by an epistemological orientation that the researcher and participants are linked and will construct the knowledge together [15-18].

A comprehensive account of interpretative phenomenological analysis has been provided by Smith et al [19]. However, for this paper it is sufficient to understand IPA as a particular qualitative approach that was developed by Jonathan Smith during the mid-1990s. It should be considered as a methodology in its own right rather than simply a means of analysing data and is based upon the fundaments of phenomenology, hermeneutics, and idiography [20,21].

IPA rigorously explores how individuals make sense of their experience and acknowledges that the researcher's interpretations are necessary in order to understand the personal world being studied $[19,22]$. Instead of attempting to provide a definitive account of a certain experience, IPA researchers engage in an interpretive activity to provide an understanding of the phenomenon based on the narrative or written account of the participant. This approach has been termed 'double hermeneutics' and involves the researcher attempting to understand the participant, who is trying to make sense of their personal experience [19].

It has been reported that some phenomenologists are reluctant to use specific steps to report their research and that imposing a method on a phenomenon could do a great injustice to the integrity of that phenomenon [23]. However, as most members of the current research team are new to phenomenological research, use of a structured, sequential approach was found to be beneficial.

The literature concerning interpretive phenomenological analysis indicates that there is no correct sample size that should be used to establish saturation. However, IPA's idiographic approach usually reflects a small sample size as the preferred method to understand the 'depth' of the experience, and not the 'breadth' of it [19].

\section{ETHICAL CLEARANCE}

Ethics approval for this study was obtained from the University of Canberra Human Research Ethics Committee. However, it also should be noted that the principal researcher had a prior prolonged engagement with the participants through his role as coach of the Erindale program. His work in this capacity provided the opportunity for close working relationships, trust and rapport to be established with a majority of the athletes. As suggested by Cohan and Crabtree [24], the development of rapport and trust facilitates understanding and coconstruction of meaning between researcher and subjects. The Erindale program members who volunteered for this study were provided with sufficient information to ensure that they had adequate understanding of the risks, benefits and purpose of the research, but the participants were also advised that they could elect to disengage with the study at any time and that this choice would not predispose them to any prejudicial judgment and/or exclusion from the training environment. The purpose of providing potential participants with information about the study and seeking their consent was not merely a matter of satisfying a formal requirement. The aim was to develop a mutual understanding between the participants and the research team [25].

\section{METHODS}

It has been suggested describing a phenomenon in sufficient detail enables readers to evaluate the extent of the conclusions and decide how they might be transferable to other times, settings, situations, and people [24]. For these reasons the following steps were used for this qualitative inquiry: 


\subsection{Selection of participants}

In keeping with the belief that phenomenological researchers need to utilize a sample that has directly experienced the phenomenon being investigated [23], a purposive sample was chosen for the study. This was done by purposefully selecting athletes who had at least two years of experience with the Erindale Box'Tag program and were thought to be the most capable of providing the researchers with a thick description of their experience [26]. It was hoped that having these provisions in place would enable the participants to provide varying first-hand accounts of the experience that when analyzed would create a detailed understanding of the Erindale Box'Tag experience [27]. In the end a 'thick' and 'rich' description of the experience was provided by three female athletes aged 27-44 yrs (M=35.7 yrs). They are introduced below, although pseudonyms have been used to protect their identity.

Molly: Is 28 years old, has no children and has been attending training three nights a week for the past two and a half years.

Jane: Is a mother of two, who is 36 years old and has been a member of the club for a little over two years.

Susan: Is 44 years old and has no children. Susan has developed her physical, technical and tactical qualities during a two-year involvement with the program.

\subsection{Data generation}

There are normally two ways in which researchers can generate data when using a phenomenological approach conducting interviews, or utilizing a written account of the experience [28]. The current study collected data from in-depth interviews as a means of obtaining first-hand accounts of the participants' training and competition experience.

The interviews were held in a private office located at Canberra PCYC. Each interview was audio-recorded and later given to a professional transcriptionist to transcribe the recordings verbatim.

Before proceeding with the analysis phase, the transcripts were provided to the participants to confirm and verify their personal accounts.

\subsection{Interview technique}

Participants were interviewed separately by the principal researcher, from whose perception the interviews were much more like a conversation between two friends than a formal question and answer session. This was probably due to the close bond that already existed and the fact that the participants and the researcher/coach regularly engaged in pre- and post-training discussions.

During the interviews the participants were initially asked a single open-ended question - "Can you please tell me about your experience with the program?". The descriptions were investigated further by use of additional open-ended 'probes' or 'prompts'. This provided an opportunity for the participants to explore their personal experiences and give a more detailed account of their participation in the Erindale program, as evident in the figure below.

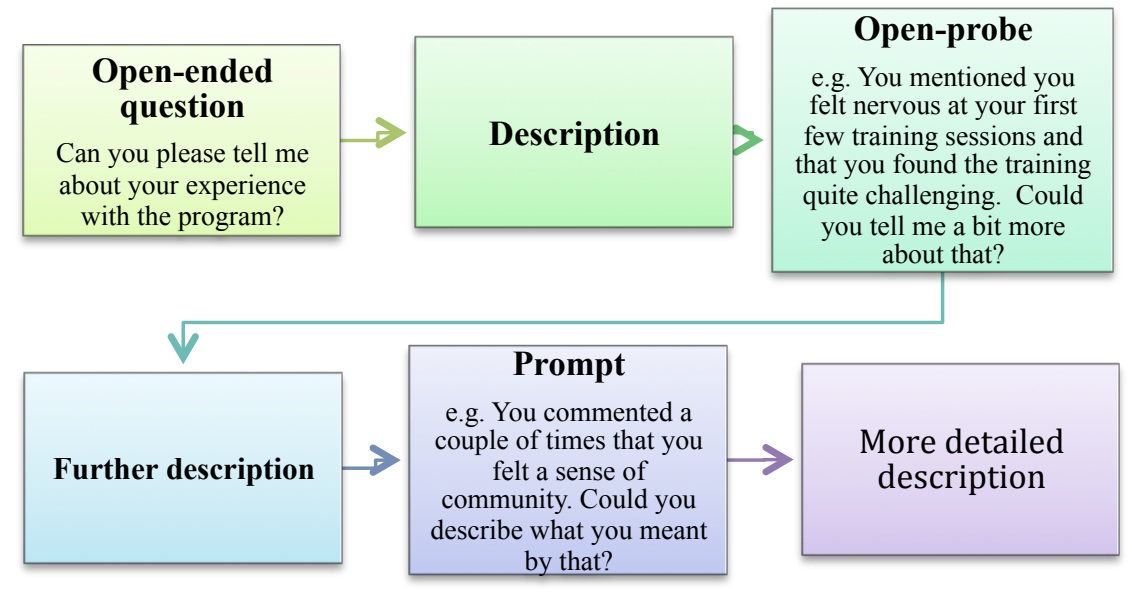

Figure 1: Overview of the interview process that was utilized to gather a rich and detailed account of each participant's experience with the Erindale Box'Tag program. 


\subsection{Data Analysis}

In an attempt to ensure that the research objectives were met, the idiographic approach of analysis outlined by Smith et al [19] was followed and the participants' transcripts were rigorously explored one case at a time. The individual accounts were then compared to identify the recurring themes within the group. The group themes that emerged were used to provide a detailed summary of the project. Figure 2 illustrates the evolutionary process of the analysis.

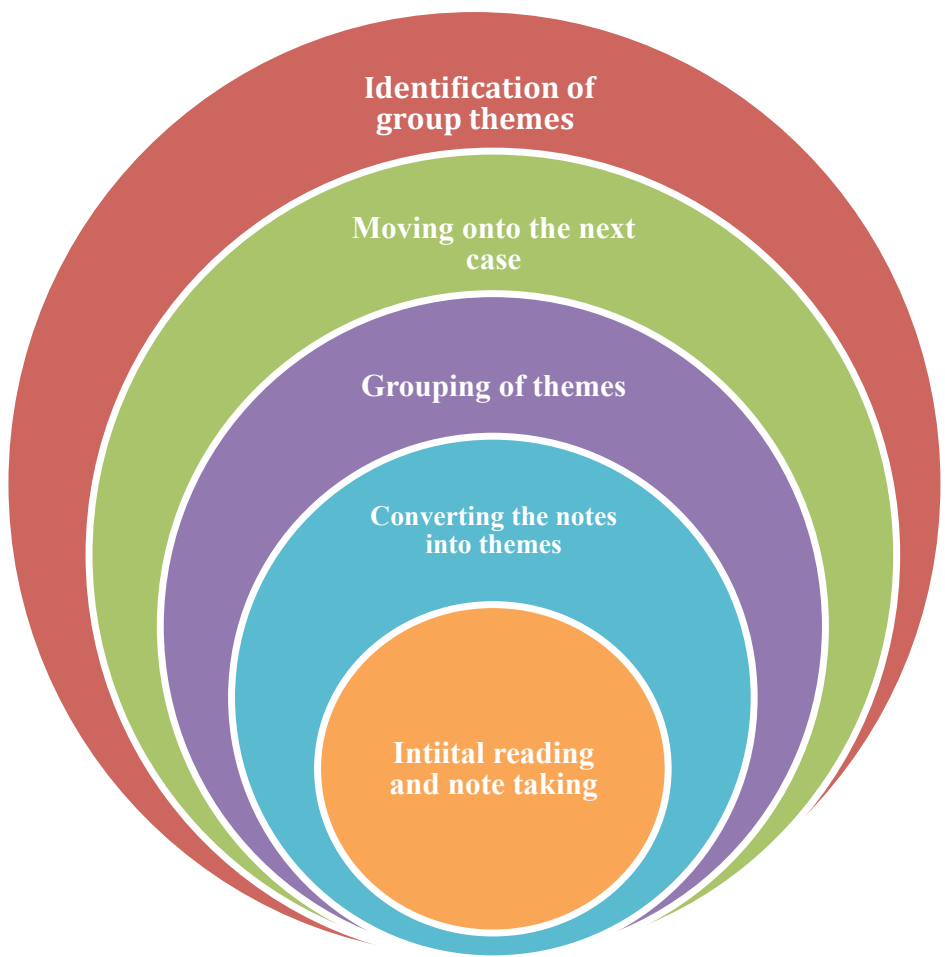

Figure 2: Schematic illustration of the steps by which data were analyzed.

\subsection{Initial reading and note taking}

The first step in the analysis process proved to be a highly time-consuming activity. It consisted of reviewing the text of the first transcript a number of times. It was found that re-reading the text provided a deeper understanding of the participant's interpretations. At this initial stage a record was simply made of any word or sentence considered potentially significant. Further exploratory notes were developed from additional reading, reviewing and then reflecting as shown in Table 1 below.

Table 1: Illustration of approach through which transcript for each participant was initially explored.

\begin{tabular}{|l|l|l|}
\hline Original Transcript & Initial Thoughts & Exploratory Comments \\
\hline $\begin{array}{l}\text { Interviewer: Can you please tell } \\
\text { me about your experience in the } \\
\text { program? }\end{array}$ & $\begin{array}{l}\text { Jane described her experience as } \\
\text { being fun, physically } \\
\text { challenging and very rewarding }\end{array}$ & $\begin{array}{l}\text { There is a sense of enjoyment } \\
\text { and goal attainment with the } \\
\text { training }\end{array}$ \\
$\begin{array}{l}\text { Interviewee: It's been a lot of } \\
\text { fun but also extremely } \\
\text { challenging and rewarding-I } \\
\text { really enjoy training here, there's } \\
\text { a real sense of camaraderie }\end{array}$ & $\begin{array}{l}\text { A feeling of sharing the } \\
\text { asperience with others is seen }\end{array}$ & $\begin{array}{l}\text { The program provides a } \\
\text { positive and rewarding } \\
\text { experience for Jane }\end{array}$ \\
\hline & & $\begin{array}{l}\text { There is an emphasis on team } \\
\text { work }\end{array}$ \\
\hline
\end{tabular}




\subsection{Converting the notes into themes}

This stage entailed working mostly with the notes that had been developed and not as much with the transcript. The aim was to identify emerging themes and structure them into concise phrases. This was achieved by employing the strategies outlined by Pietkiewicz and Smith [20] and selecting the comments that were considered to be at a slightly higher level than abstract. Once identified, these emerging themes were listed in a separate column for further analysis. The following table is an example of the way in which emerging themes were selected from the original transcript.

Table 2: Example of approach to conversion of initial thoughts and exploratory comments to emergent themes for each participant

\begin{tabular}{|l|l|l|}
\hline Initial Thoughts & Exploratory Comments & Emerging Themes \\
\hline $\begin{array}{l}\text { Jane described her experience as } \\
\text { being fun, physically } \\
\text { challenging and very rewarding }\end{array}$ & $\begin{array}{l}\text { There is a sense of enjoyment } \\
\text { and goal attainment with the } \\
\text { training }\end{array}$ & $\begin{array}{l}\text { A great deal of personal } \\
\text { satisfaction is achieved by Jane } \\
\text { when she successfully masters } \\
\text { challenging exercises and } \\
\text { complex training drills }\end{array}$ \\
$\begin{array}{l}\text { A feeling of sharing the } \\
\text { experience with others is seen as } \\
\text { important }\end{array}$ & $\begin{array}{l}\text { The program provides a positive } \\
\text { and rewarding experience for } \\
\text { Jane }\end{array}$ & $\begin{array}{l}\text { Jane experiences a sense of } \\
\text { community }\end{array}$ \\
& $\begin{array}{l}\text { There is an emphasis on team } \\
\text { work }\end{array}$ & \\
\hline
\end{tabular}

\subsection{Grouping of themes}

This phase of the analysis involved an attempt to discover the similar patterns in the emerging themes. The purpose here was to group the related cases together based on their theoretical similarities. The process involved developing themes for the entire transcript before eliminating the ones that did not appear to fit in with the emerging structure. Once identified, the major themes were grouped together in a table based on their conceptual nature as evident in Table 3.

Table 3: An interpretative phenomenological representation of the major themes arising from the original transcript

\begin{tabular}{|l|l|l|}
\hline The experience & \multicolumn{1}{|c|}{ The coach } & The training \\
\hline Positive & Positive & $\begin{array}{l}\text { Physically and mentally } \\
\text { challenging }\end{array}$ \\
Challenging & Supportive and encouraging & Safe \\
Rewarding & Knowledgeable & Structured \\
Exciting & Empowering & Positive \\
& & Purposeful \\
\hline
\end{tabular}

\subsection{Moving onto the next case}

In keeping with the idiographic commitment of IPA the other two transcripts were comprehensively explored one case at a time. Rigorously following the same process for each case separately allowed new themes to emerge independently of each other.

\subsection{Identification of group themes}

By comparing the data of the three individual tables it was possible to develop the major themes for the group. This process involved identifying and selecting the recurring themes that connected the separate versions together and that when combined would provide a richer account of the group experience [19]. 


\section{RESULTS}

An analysis of the group data revealed three predominant themes. However, it is worth noting that these themes were underpinned by a number of overlapping and intertwined descriptions and comments. For example, when describing the environment the participants expressed it as challenging and rewarding and then they reused the same words to define the training.

Presented below are the three major themes that represent the contributing factors that have influenced Jane, Susan and Molly's two-year involvement with the Erindale Box’Tag program.

\section{- The program provides a sense of belonging \\ - The coach-athlete relationship \\ - The training}

\subsection{Theme 1: The program provides a sense of belonging}

The emergence of the first theme highlights a fundamental and very important human desire. According to Bollen and Hoyle [29] a sense of belonging measures individuals' perceived social cohesion to groups and/or environments, and occurs when the defining attributes, or characteristics of the concept, are evident [30].

Susan described how she felt a sense of belonging when she said "The environment itself is a major factor why I come here. In the couple of years previously I'd joined a couple of gyms in the hope of losing weight and knew that physical activity can help with depression. But in those environments I became more self-conscious. I didn't feel comfortable because of the type of people that frequented them and the lack of support and encouragement. So in some instances I only went in once and then didn't return, but at the PCYC I didn't feel there was any judgement or criticism of me - physically or otherwise, I just felt really comfortable. I immediately felt part of something quite unique. I could see that it was having a positive effect on me in a really short space of time. I felt like I was a part of something special - like doing the run through and slapping hands; it's like an acknowledgement of being there and finishing the session. So there are lots of little things I think that add up to just a really big impact".

Molly shared this view when she noted " There's really good camaraderie here and it feels like you're part of something unique. I think it's a really supportive and positive environment, like everyone's really encouraging. Everyone wants to do their best and you encourage us all to make sure we do. I think that's always nice in a sort of environment like this. I think if you've got a good environment you're more likely to put in extra effort. Whereas, if you're not really having fun and not with people who have similar values you're just going there for the slog, then you do your thing and you leave. Whereas having people around you, who all want to perform to their best, then I think that always makes a big difference to how well you perform, which in turn affects everything".

When recounting how she felt a sense of belonging, Jane said "I've been training for two years now and I guess to keep at something for two years, for me, says that I really enjoy it. There's definitely a sense of community with the training group and a feeling of knowing and respecting each other. It is a very supportive and positive place to train".

\subsection{Theme 2: The coach-athlete relationship}

A positive and supportive coach-athlete relationship has been described as important for enhancing the motivation of athletes [31] and for developing athletic performance [32]. The importance of the coach-athlete relationship for Susan, Molly and Jane is evident from the comments below.

"I've never felt ever that someone would think of me as an athlete. So I think fundamentally, just putting that out there and saying you're athletes and you're not just coming off the street and trying to get fit, you're actually skilled and you'll become more skilled through consistent training and a desire to continually improve. Having those expectations on you and rising to meet those challenges I think is primarily the major difference with what we do". - Jane

"I've never considered myself as an athlete but now I do, and it has made such a difference with the way I view my training and has even changed my outlook on life. Like I mentioned earlier the reason I started attending was because I was overweight and suffering from depression. I think it's amazing the positive effect this has had on my life - training here has got me out of a space that was really unpleasant and uncomfortable to be in". - Susan

"There's a sense of working together when we train-it's always encouraging and very supportive. Even though you're the coach it's not like you're saying I'm the boss, I know everything and you can only do things my way. It's more like you want to help and support us to become the best we can be". - Molly 


\subsection{Theme 3: The training}

Two different but equally important sub-themes emerged as the most significant factors concerning the training.

Providing purpose: This sub-theme illustrates how a progressive, structured and carefully planned training program enhanced the training experience for Molly, Jane and Susan and contributed to their two-year involvement with the program.

Jane revealed how her training provided a sense of purpose for her when she compared it to a previous experience. "Before this I did other types of training but when I was doing gym classes, I quickly realized I was just a number and basically following a person out the front who was telling everybody what to do. There was no real focus on what you were doing, basically it's just doing something without any purpose or understanding why. What I find with this program though is a rationale for the training and a focus on progressing, which brings everything together.

Later in the interview Jane went on to explain how experiencing Box'Tag competition provided further meaning for her training when she added. "While I was in the ring I wasn't thinking about I have to hit, I have to win - I was thinking about, what's my next move? All this stuff we'd been learning was going through my head. I guess I was suddenly seeing everything I'd been doing, it was like, OK now, I understand what I've been doing and it felt great, because every week I'd be learning and developing and, all of a sudden, the application of it worked out and made so much sense".

Susan echoed Jane's comments when she shared her thoughts about competition. "Being in the ring with someone you've been training with is a great opportunity to display some of the things that we've learnt. I felt that even though nothing was said we were able to acknowledge each other's training and the amount of hard work we had put in. It was after my first competition that I recognized how everything we've been doing fitted in'”.

Susan went onto describe how the progressive nature of the training provided a sense of purpose for her by explaining. "It's been two years now and I still get a buzz and excitement from the training. It's like each time we train, you discover how to do something a little better. Looking back, I can see how everything we do is linked and how it all connects. Even some of the stranger exercises like hopping while you punch makes sense to me now. I guess I had never really made the link before".

The training also proved to be meaningful for Molly, who described it as 'having a reason and a real purpose to it'. When asked if she could elaborate on what she meant by this, Molly replied, "Well, I've never felt like we train just for the sake of it, there is always a reason for everything we do. Like, we learn skills at some of our sessions and develop our fitness at other ones and then put it all together by demonstrating our fitness and skills in the ring".

A focus on safety: The importance of participating in a modified, low-risk form of boxing with an emphasis on safety quickly became apparent in all three interviews. The focus on safety is evident from the following extracts.

"I guess I've always been a little worried about being punched, even though I know it's modified and you can't get hit in the head I still worry a bit about being punched hard. So for me, the development of the new gloves has been very important and demonstrates a real focus on providing a much safer form of boxing. There's just no way I can imagine these things hurting you, even with as much force as someone wanted to put behind them, so for me the fear of getting hurt is gone".- Susan

"I've always been interested in boxing as a sport, my eldest brother used to watch boxing and he would talk to me about it. He would talk about the strategy -he appreciated the finer points rather than the hitting. So I guess that influenced me to want to learn boxing but I never really pursued it because I wouldn't want to get hurt, so for me Box'Tag has been perfect - I get to learn the skills, get fit and train like a boxer but know I won't get hurt". - Jane

"I'm not interested in boxing and I certainly wouldn't want to punch someone in the face, or have mine punched for that matter but what we do is different. There's a strong emphasis on safety and having fun, everyone knows it's not about trying to hurt each other and that comes through really clear with your coaching". -Molly

\section{DISCUSSION}

The present study utilized an interpretative phenomenological analysis to discover the contributing factors that have influenced three community-based athletes to have a two-year involvement with a modified, low-risk form of boxing.

For Molly, Susan and Jane a sense of belonging was perceived as 'essential' for their continued engagement with the program. This finding is consistent with the observations of other researchers $[33,34]$ who provide examples of how sporting programs and recreational actives can give participants a sense of belonging.

McMillan and Chavis [35] argue that there are a number of elements required to facilitate a sense of 
belonging between individuals and a community - or in this case athletes and a sporting program. They regard 'faith' as an important first step in the process and describe how individuals wanting to belong maintain a certain belief that they will be accepted. Having this faith represents a risk and requires a certain amount of courage on the part of the individual, as they could be embarrassed and humiliated if they are made to feel unwelcome by the community. The following statement from Jane demonstrates how she acted with good faith when she wanted to be apart of the program. "It was quite challenging at first, coming in. I was a little nervous and intimidated, I was unsure if I would fit in but I really enjoyed the training and the atmosphere and wanted to keep coming" - Jane.

The second element regarded by McMillan and Chavis [35] as critical to development of a sense of belonging is 'acceptance' as an indication of the community's response to the display of faith. It is contended that communities have a responsibility to accept individuals and welcome them as members once an individual has acted with good faith and when the acceptance occurs the individual develops a stronger attraction to the community. Bonds are developed between people when they believe they are wanted and welcomed. In the context of the present study, the development of this bond is evident in the following passage: "I didn't feel like I belonged straight away but I always felt really welcomed".-- Jane.

'Cognitive dissonance' is the third requirement identified by McMillan and Chavis [35] for facilitation of a sense of belonging. It is considered essential that communities test new members to determine if they are willing to invest time and effort into becoming active and effective contributors. This idea of 'having to pay her dues' before she felt accepted was described by Jane when she said "I found I had to put in before I got a sense of community - it was like I was being tested to see if I would stick with it, then it morphed into this feeling like I belong",

Molly, Susan and Jane also attributed the coach-athlete relationship as an important influence for their twoyear affiliation with the program and described the coaching as "empowering, supportive and personal". The emergence of this theme suggests the autonomy-supportive coaching approach utilized in the program could have positively influenced the motivation and satisfaction of Molly, Susan and Jane, resulting in their prolonged engagement. This suggestion is consistent with the views of Deci and Ryan [36] and Vallerand and Losier [37]. They believe that social factors (in this case the behavior of the coach can influence athletes' motivation indirectly by satisfying three psychological needs - competence, autonomy and relatedness - which, in turn, can nurture athletes' intrinsic motivation and self-determined types of extrinsic motivation. Mageau and Vallerand [38] have presented seven coaching behaviors that may assist in promoting athletes' perception of competence, autonomy and relatedness: (1) providing athletes with choices; (2) providing athletes with rationales for tasks; (3) acknowledging the feelings and perspectives of athletes; (4) giving athletes opportunities for initiative taking and independent work; (5) providing athletes with information and feedback regarding their competence on a task or skill; (6) avoiding controlling behaviors; and (7) creating a task-focused rather than ego-focused environment.

It would appear that Molly, Susan and Jane have identified with some of these coaching behaviors, resulting in the development of three very positive and supportive coach-athlete relationships and the creation of a training environment that assists in nurturing and developing the self-determining motivation of the athletes.

The final theme that emerged from the analysis was a focus on the training. For Molly, Susan and Jane the training was perceived as being 'purposeful', 'challenging' and 'rewarding'. This finding is consistent with the literature on sport participation, which indicates that a sense of achievement, skill development, fitness enhancement, increased levels of self-esteem, enjoyment and family and social influences are the significant motivators for participation in sport and/or other physical activities [39-41]. The perception of benefit associated with training incorporating a sense of purpose is also compatible with the observations of Wacquant [11] who conducted a comprehensive three-year ethnographic study of a boxing gym in a Chicago ghetto. He discovered that the boxers who frequented the gym considered training an integral part of their lives. The boxers believed that training provided the opportunity to develop the physical attributes and technical proficiencies required to be successful in boxing. They felt that success in boxing required preparing the body to withstand the physical demands of the sport and developing technical skills that could only be acquired through many years of rigorous, dedicated practice [11].

The dedication and commitment to training as well as the willingness to undergo many hours of hard work in the quest for developing and improving relevant physical qualities and technical skills is as evident for Molly, Susan and Jane as it was for the boxers studied by Wacquant. However, the 'emphasis on safety' described by Molly, Susan and Jane as being 'extremely important' is at odds with the opinion of the boxers. The participants in this study considered 'not being able to hit to the head', 'using impact absorbing gloves' and 'not intentionally harming anyone' as 'vital' for their involvement with the program. These views are totally inconsistent with the boxers' perceptions - they accepted the possibility of being injured and considered the risk as a part of their job. Nonetheless, $80 \%$ of the boxers indicated they would not want their children to be involved with boxing [11]. Although the reasons for the boxers concerns' are not expressly outlined, it is 
reasonable to conclude that the boxers had some misgivings in regard to exposing their children to the inherent dangers associated with boxing participation.

The Erindale program's 'emphasis on safety' is based on unequivocal evidence that participation in boxing entails serious risk. It has been estimated that the condition popularly known as punch-drunkenness develops in about $20 \%$ of professional boxers, and there is evidence that amateur boxers can also incur neurological damage. Ongoing improvements in the regulation and medical supervision of professional and amateur boxing might reduce the inherent injury risks associated with the sport but cannot eliminate them [42-44]. It should be noted that Molly, Susan and Jane considered these risks as 'unnecessary', 'avoidable' and 'inappropriate' and noted that the emphasis on safety has a major influence on their involvement with the Erindale program.

\section{CONCLUSION}

Although the current study provides a detailed and rich description of athlete experiences of the Erindale Box'Tag program, the findings are limited to the responses of three participants and therefore cannot be considered as necessarily providing a representative view of all people involved in the program. Nevertheless, it is hoped this paper can act as a suitable starting point for future pertinent research. Interviewing additional athletes from the Erindale program and including the perceptions of some of the younger athletes and the views of their parents could significantly increase the understanding of why some people are choosing to participate in a form of boxing that is much safer than the traditional version.

Alternatively or as well, further research that examines each of the major themes presented in this paper could be conducted. For example, in the current study the participants considered the coach-athlete relationship as a significant factor for their prolonged engagement with the program. However, Molly, Susan and Jane did not fully describe why they thought the coaching was effective. Therefore future research into the perceived coaching practices that have influenced participation in a modified, low-risk boxing could prove to be instructive.

\section{REFERENCES}

[1]. Perkins, P., Hahn, A., Lucas, R. and Keegan, R., The Boxing Conundrum: Is there a place for a new variant of the sport? Quest Journal of Research in Humanities and Social Science 2014. 2(9): p. 09-25.

[2]. Attwood, A., Loosemore, M. and Knowles, C., Amateur Boxing Association of England Ltd Offficial Handbook. 2003, London UK: Fox Promotions Media.

[3]. Massimilliano, B., Loosemore, M., Gianlorenzo, D., Palmieri, V., Faina, M., and Zeppilli, V., Amateur boxing in the last 59 years. British Journal of Sports Medicine, 2013. 47(7): p. 452-457.

[4]. Svinth, J., Death under the spotlight: analysing the data. Journal of Combative Sport, 2007. November: p. 1-19.

[5]. Lundberg, G.D., Medical arguments for nonparticipation in boxing, in Medical ASpects of Boxing, J. Bd, Editor. 1993, CRC Press: Florida USA. p. 11-15.

[6]. Beran, R. and Beran, J., The law(s) of the rings: boxing and the law. Journal of Law and Medicine, 2009. 16(4): p. 684-695.

[7]. Pagelow, M. and Pagelow, F., Alternative views on family violence, in Family Violence. 1984, Praeger Publishers: New York USA. p. 107-143.

[8]. World Health Organisation, The World Health Report: Reducing Risks, Promoting Healthy Life. 2002: Geneva, Switzerland.

[9]. Metcalf, A., The summer's hottest workout: boxing gyms are the newest trend, in examiner.com. 2013: Illinois USA.

[10]. Didomenico, T., Why Boxing? , in Family Times: The Parenting Guide of Central New York. 2012: New York USA.

[11]. Wacquant, L.J.D., The pugilistic point of view: how boxers think and feel about their trade. Theory and Society, 1995. 24(4): p. 489-535.

[12]. Scott, D., The Art and Aesthetics of Boxing. 2009, Lincoln Nebraska: University of Nebraska Press. 204.

[13]. Chandler, D., Introduction: The Pictures of Boxing, in An Anthology of Writings on Boxing and Visual Culture, J.G. David Chandler, Tania Guha, Gilane Tawadros, Editor. 1996, Institute of the Visual Arts: London UK. p. 13-26.

[14]. American Medical Association, 1999 Meeting of the American Medical Association: Reports of the Council on Scientific Affairs, in 1999 Meeting of the American Medical Association: Reports of the Council on Scientific Affairs; Boxing Injuries. 1999. p. 6-7.

[15]. Whittemore, R., Chase, S.K. and Mandle, C.L., Validity in Qualitative Research Qualitative Health Research 2001. 11(4): p. 522 $-537$.

[16]. Packer, M.J. and Goicoechea, J., Sociocultural and Constructivist Theories of Learning: Ontology, Not Just Epistemology.Educational Psychologist 2000. 35(4): p. 227-241.

[17]. Krauss, S.E., Research paradigms and meaning making: A primer. The qualitative report, 2005. 10(4): p. 758-770.

[18]. Guba, E. and Linclon, Y.S., 'Competing Paradigms in Qualitative Research', in N. K. Denzin and Y. S. Lincoln (eds) Handbook of Qualitative Research. 1994, Sage Thousand Oaks, CA. p. 105-117.

[19]. Smith, J.A., Flower, P. and Larkin, M., Interpretative Phenomenological Analysis, Theory, Method and Research 2009, London: Sage Publications Ltd.

[20]. Pietkiewicz, I. and Smith, J.A., Praktyczny przewodnik interpretacyjnej analizy fenomenologicznej w badaniach jakościowych w psychologii. Czasopismo Psychologiczne, 2012. 18(2): p. 361-369.

[21]. Smith, J.A., Harre, R. and Van Langenhove, L., Idiography and the case study. In J. A. Smith, R. Harre \& L. Van Langenhove (Eds.) Rethinking Psychology. 1995, London: Sage.

[22]. Chapman, E. and Smith, J., Interpretative Phenomenological Analysis and the New Genetics. Journal of Health Psychology, 2002. 7: p. 125-130.

[23]. Hycner, R.H., Some guidelines for the phenomenological analysis of interview data. In A. Bryman \& R. .G. Burgess (Eds.), Qualitative research. Vol. 3 1999. 143-164.

[24]. Cohan, D. and Crabtree, B. "Qualitative Research Guidelines Project.". http://www.qualres.org/HomeProl-3690.html, 2006.

[25]. Australian Health and Medical Research Council. National Statement on Ethical Conduct in Human Research, 2007, N.H.A.M.R. Council, Editor. 2007 
[26]. Patton, M., Qualitative Research and Evaluation Methods. 2002, Thousand Oaks, CA: Sage Publications

[27]. Polkinghorne, D.E., Phenomenological research methods. In R. S. Valle \& S. Halling (Eds.), Existential-phenomenological perspectives in psychology. 1989, New York.

[28]. Giorgi, A., The descriptive phenomenological method in psychology: A modified Husserlian approach. 2009, Pittsburgh, PA: Duquesne University Press

[29]. Bollen, K.A. and Hoyle, R.H., Perceived cohesion: A conceptual and empirical examination. Social Forces 1990. 69(2): p. 479504.

[30]. Walker, L.O. and Avant, K.C., Stratergies for theory construction in nursing (2nd ed.). . 1988, Connecticut: Appleton-CenturyCrofts.

[31]. De Swardt, A., The relationship between the coach and the athlete. The Coach, 2004. 23: p. 32-36.

[32]. Vealey, R.S., Armstrong, L., Comar, W. and Greenleaf, C.A., Influence of perceived coaching behaviors on burnout and competitive anxiety in female college athletes. Journal of Applied Sport Psychology 1998. 10: p. 297-318.

[33]. Sturts, J. and Ross, C., Collegiate Intramural Sports Participation: Identified Social Outcomes. International Journal of Sport Management Recreation \& Tourism, 2013. 11: p. 25-41.

[34]. Townsend, M., Moore, J. and Mahoney, M. Playing their part: the role of physical activity and sport in sustaining the health and well being of small rural communities. The International Electronic Journal of Rural and Remote Health Research, Education, Practice and Policy 2002. 2.

[35]. McMillian, D.W. and Chavis, D.M., Sense of community: A definition and theory Journal of Community Psychology, 1986. 14(1): p. 6-23.

[36]. Deci, E.L. and Ryan, R.M., Intrinsic motivation and self-determination in human behavior. 1985, New York: Plenum.

[37]. Vallerand, R.J. and Losier, G., An integrative analysis of intrinsic and extrinsic motivation in sport. Journal of Applied Sport Psychology, 1999. 11: p. 142-169.

[38]. Mageau, G.A. and Vallerand, R.J., The coach-athlete relationship: A motivational model. Journal of Sports Sciences 2003. 21: p. 883-904.

[39]. Crone-Grant, D.M. and Smith, R.A., Broadening horizons: a qualitative inquiry on the experience of patients on an exercise prescription scheme. Journal of sport science 1999. 17(12).

[40]. Allender, S., Cowburn, G. and Foster, C., Understanding participation in sport and physical activity among children and adults: a review of qualitative studies. Health Education Research Theory \& Practice, 2006. 21(6): p. 826-835.

[41]. Australian Bureau of Statistics. Motivators and Constraints to Participation in Sport and Physical Recreation. 2007.

[42]. Sawauchi, S., Murakami, S., Tani, S., Ogawa, T., Suzuki, T., and Abe, T., Acute subdural hematoma caused by professional boxing. No Shinkei Geka, 1996. 24(10): p. 905-11.

[43]. Jordan, B., Chronic traumatic brain injury associated with boxing. Seminars in Neurology 2000. 20(2): p. 179-185.

[44]. Clausen, H., Mccrory, P. and Anderson, The risk of chronic traumatic brain injury in professional boxing: change in exposure variables over the past century. British Journal of Sports Medicine, 2005. 39: p. 661-664. 